\title{
Dr. Anthony Lang: Canadian Leaders in Neurology
}

\author{
Jane Liao
}

Keywords: Movement disorders, Communication, Neurology - Education

doi:10.1017/cjn.2020.20

Can J Neurol Sci. 2020; 47: 410-411

The Canadian Leaders in Neurology series are an initiative of the Canadian Neurological Society whose objective is to showcase exceptional accomplishments by Canadian neurologists who are leaders in their respective fields. In this segment of the series, Jane Liao, a neurology resident at University of Toronto, interviews Dr. Anthony Lang (Figure 1).

Dr. Lang is well-recognized as a world leader in movement disorder having had more than 700 peer-reviewed publications and 89,000 citations under his belt. He is a professor at the University of Toronto where he holds the Jack Clark Chair for Parkinson's Disease Research. He is also the Director of the Edmond J. Safra Program in Parkinson's Disease and the Morton and Gloria Shulman Movement Disorders Clinic and holds the Lily Safra Chair in movement disorders at Toronto Western Hospital.

Jane Liao (JL): So Dr. Lang, why neurology and why movement disorder?

Anthony Lang (AL): I was promised a position in the Cardiology program, but I did a rotation in Neurology just to do it. I was on call one weekend and I was high as a kite the whole weekend! I was just seeing incredibly different stuff. Every patient was unique, every exam was different, and the exams were critical in combination with the history in determining what the problem was.

I also happened to be training with one of my mentors, Dr. Joseph Marotta, who was a phenomenal teacher. He would bring a Parkinson's patient to these teaching sessions by the name of Mr. WD. I always remember Mr. WD because I subsequently took care of him. He would sit there having not taken his levodopa, like a statue, then he would take it in front of us and switch on like a light bulb. It was enlightening and thrilling.

\section{JL: Of the mentors you have had, you speak a lot of Dr. David} Marsden. What is the impact he had on your career?

AL: (Dr. Marsden) was tough. I came back to North America during my fellowship and we attended a conference together in New York City. I was presenting for the very first time internationally, I was concerned, anxious, and jet-lagged. He leaned into me. "What are you doing? You haven't come up with anything novel." I didn't learn until many years afterwards that he had told people that my presentation was the best at the meeting. People looked for gratification and he often didn't necessarily offer that, but he was a brilliant teacher. He drove you to think outside the box and I try to do that with our residents all the time.

Another brilliant, but different, gentle and incredibly observant teacher who mentored me was Dr. Stan Fahn from New York. He would invite junior faculty like myself to come to international meetings. I would sit at the back of the room and he'd ask "Dr. Lang, what do you think?". I would think "Why does he care what I think, it's incredible he would ask me what I thought of the problem." He was obviously bringing the best out of young people.

In fact, when the Movement Disorder journal was founded, Drs. Marsden and Fahn invited me onto the first editorial board. When they had completed a decade as editors, I was very fortunate that Dr. Fahn then chose me as his successor.

\section{JL: What about neurology gets you up in the morning?}

AL: It's fun! The things you see, the patients you are involved with, the speciality that you are doing, if it doesn't make you want to get up in the morning, you have to change your course. I still really enjoy seeing patients, learning new things, questioning the "holy cows," and seeing new breakthroughs.

One of the things I really want is to see a change in the natural history of the really bad diseases we deal with, like progressive supranuclear palsy (PSP), multiple system atrophy, and corticobasal degeneration. These patients suffer horribly. Whether I will or not, God only knows, but at least I'm trying to participate in work that may change things.

One of the things we need to do in these neurodegenerative diseases is to parse out subcomponents because it may be that trying to address everybody as if they have the same disease pathogenesis is one of the reasons why we have failed all along. We enroll everyone with "early untreated Parkinson's Disease" in disease-modifying trials as if they've all got the same thing. It is highly likely they don't. We have a whole list of failures but maybe they failed for the wrong reasons. Maybe we will find something effective for a very small proportion of patients, but that is better than nothing.

From the Division of Neurology, University of Toronto, Toronto, Ontario, Canada Received January 12, 2020. Date of Acceptance January 13, 2020.

Correspondence to: Jane Liao, Division of Neurology, University of Toronto, St. Michael's Hospital, 30 Bond Street, 3 Shuter, Office 3-040 (3rd Floor), Toronto, Ontario M5B 1W8, Canada. Email: zyjane.liao@mail.utoronto.ca 


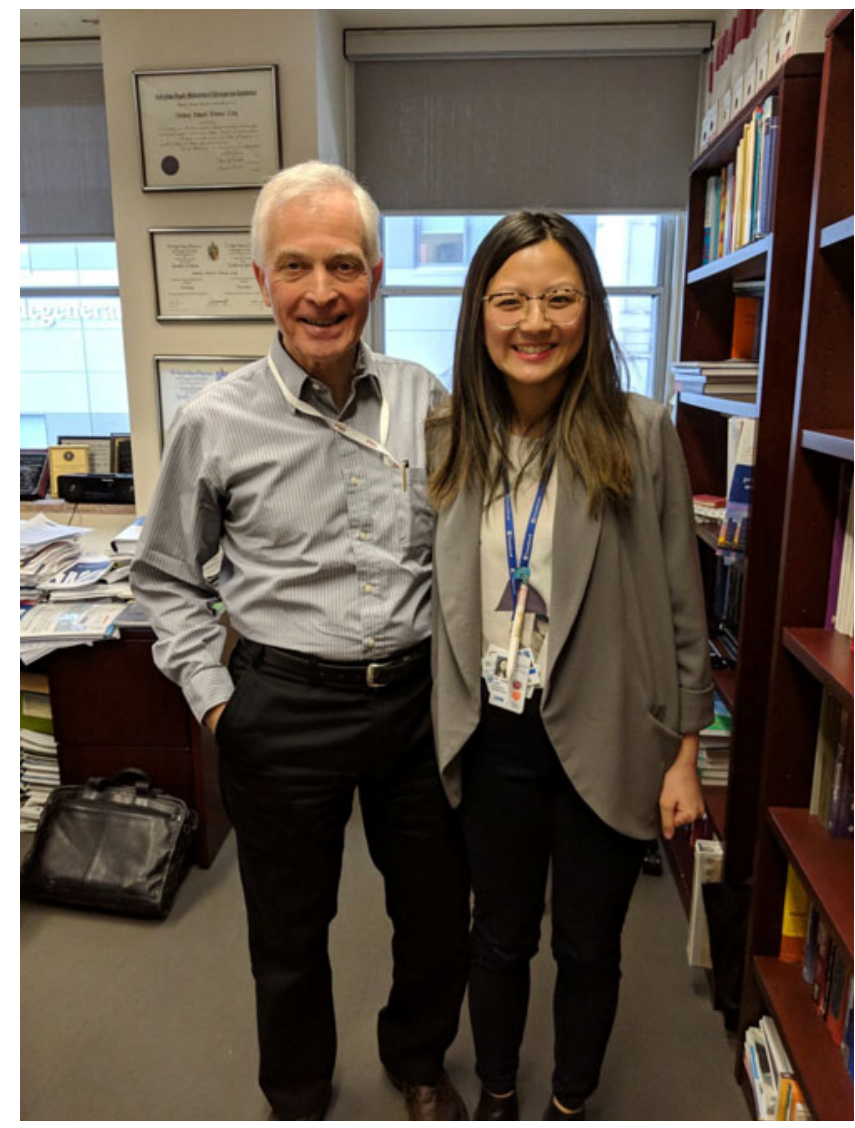

Figure 1: Dr. Anthony Lang (left) in his office, with Dr. Jane Liao (right), neurology resident, who conducted the interview.

\section{JL: Which, of the many projects that you are currently} involved with, are you most excited about?

AL: I am especially excited by the prospect of developing a new clinical and research program in PSP here in Toronto with the generous support of a patient and his family. This is particularly gratifying given that Toronto is the home of PSP. We are hoping that the research that comes from this program will have an important impact on our understanding and future management of this terrible neurodegenerative disorder.

\section{JL: How does the field today differ from what it was like when you started in neurology?}

AL: Fortunately, lots of smart people are doing neuroscience and recognizing the potential in neuroscience. That is, for you guys, the residents, really exciting. We've got so much more to learn, it is really going to be quite phenomenal to experience the impact of new technology on neurological diseases.

I was the co-author of a two-person book in movement disorders. I was very proud of it and people really claimed it was the best book in movement disorders at the time. At that time, "olivopontocerebellar atrophy" was this single disorder where some people had genetic forms and others did not. Things then changed completely, and now we have spinocerebellar ataxia, we have multiple genes, and sporadic olivopontocerebellar atrophy was probably most likely multiple system atrophy. We began to write a new edition, but I hit a wall having to rewrite this section that had become almost unmanageable. The field had changed completely.

\section{JL: What is (one of) your proudest professional/academic achievements?}

AL: My proudest achievement is being awarded the position of Officer in the Order of Canada. This was a tremendous honor and I am extremely proud to serve as an ambassador of our country internationally, highlighted by the pin in my lapel.

\section{JL: Is there anything you would've done differently in your career?}

AL: In my academic career, I might have spent more time in the lab. In fact, when I first started, I started in the pharmacology lab working with rats. I would've been interested to retain some capability in that field. Electrophysiology was another area I was very interested in, particularly related to movement disorders.

On the personal side, I would have spent more time with my children. You end up doing what you do and reaching a point of international renown by spending a huge amount of time working. I love where I am and I enjoy what I do, but without a spouse who really supported it, and maintained a connection with our kids, it would've turned out very differently. Life work balance is something that people have a better understanding of now.

\section{JL: What would you do if not medicine?}

AL: I was going to become a mathematician. In Grade 13, I had 99\% in Algebra and 100\% in Geometry. Math was a natural choice, I was going be a whiz! First year of university, at the University of Toronto, there were many math courses. Math 140 was the real toughest, 139 was the next toughest, then it went down to 101. I took 139 and realized I was with a bunch of people who were wired differently than I was. They were brilliant, and I was struggling to understand the concepts. I quickly realized math wasn't what I was going to continue. I looked around and said "What can I do? Medicine!".

\section{JL: What's one thing we'd be surprised to learn about you?}

AL: I used to compose folk music and play in a folk band when I was in high school. I still love folk music and blues. A very good friend of mine, a girl who was a friend of his family's and I played in a group that emulated Peter Paul and Mary, a very famous folk trio at the time.

Recently, I picked up the guitar again, because this good friend (my best man), turned 68 in the past year. All the males in his family preceding him had died before the age of 68 so he had a celebration of his life beyond 68. We had a ball! Simon and Garfunkel performed this song "Old friends" about two elderly individuals sitting on a park bench. It's a nice song that we used to perform, so we relearned it for the party. I'm not quite ready for the park bench yet but we enjoyed playing it again.

\section{ACKNOWLEDGEMENTS}

The Canadian Leaders Segment is conceptualized by the Canadian Neurological Society. The author would like to thank the Canadian Neurological Society resident representatives for their support and guidance in the completion of this article.

\section{Disclosures}

The author has no conflict of interest to declare. 